\title{
The occurrence of the psychosomatic symptoms during the coronavirus pandemics
}

\author{
Radka Zidkova ${ }^{1,2^{*}}$, Klara Malinakova ${ }^{1}$, Jitse P. van Dijk $k^{1,2,3}$ and Peter Tavel ${ }^{1}$ \\ ${ }^{1}$ Olomouc University Social Health Institute, Palacky University Olomouc, 77111 Olomouc, Czech Republic \\ ${ }^{2}$ Department of Community and Occupational Medicine, University Medical Center Groningen, University of \\ Groningen, 9713 AV Groningen, The Netherlands \\ ${ }^{3}$ Graduate School Kosice Institute for Society and Health, P.J. Safarik University in Kosice, 04011 Kosice, Slo- \\ vak Republic \\ * Correspondence: ; Tel.: +420-728-407-390
}

Publisher's Note: MDPI stays neutral with regard to jurisdictional claims in published maps and institutional affiliations.

\section{(c) (1)}

Copyright: ( $) 2020$ by the authors. Licensee MDPI, Basel, Switzerland. This article is an open access article distributed under the terms and conditions of the Creative Commons Attribution (CC BY) license (http://creativecommons.org/licenses/by/4.0/).

\begin{abstract}
This paper explores the relationship between the coronavirus pandemic, together with associated measures taken to combat it, and the occurrence of a wide range of psychosomatic symptoms in the COVID-19-free population. The results showed associations between the coronavirus pandemic and increase of psychosomatic symptoms (in 3.2-17.3\% respondents) and negative emotions (in 9.9-33.3\% respondents). Among the risk factors associated with a higher risk of increased frequency of health complaints are younger age, female gender, negative emotions and potentially, also highest achieved secondary school education, student status and high spirituality. Our findings suggest that the coronavirus pandemic is having a significant influence on the prevalence of psychosomatic health complaints and emotional state of people.
\end{abstract}

Keywords: coronavirus pandemic; COVID-19; psychosomatic symptoms; health complaints

\section{Introduction}

In December 2019 Wuhan, China, became the center of an outbreak of a pneumonia of unknown cause [1]. The World Health Organization (WHO) officially named this disease coronavirus disease 2019 (COVID-19) and labelled the virus as "severe acute respiratory syndrome coronavirus 2" (SARS-CoV-2) [2]. Depending on the expansion of the virus around the world, most state authorities of individual countries put into place various measures to stop the spread of the SARS-CoV-2 virus. This difficult situation influenced various aspects of human life and affects their mental and physical health.

Current research has revealed a profound and wide range of psychosocial impacts on people at the individual, community and international levels during the coronavirus pandemic. On an individual level, people experienced anxiety, depression [3-7] and stress [4-7]. In their study, Wang et al. [4] found that $53.8 \%$ of respondents rated the psychological impact of the coronavirus pandemic as moderate or severe. Stress caused by the current situation may not only lead to psychological changes, as mentioned above, but can also affect physiological (somatic) function, leading to an occurrence of psychosomatic symptoms. A large body of research has shown significant associations between perceived stress and psychosomatic complaints [8-10].

At present, only a few studies exist that mention the impact of the COVID-19 pandemic on the incidence of psychosomatic symptoms [3,4,11,12] and to the best of our knowledge, this is one of the first studies examining the effect of the coronavirus pandemic, together with its associated measures, on the occurrence of a wide range of psychosomatic symptoms in COVID-19-free respondents. Furthermore, the effect is compared to the occurrence of psychosomatic symptoms before and during the coronavirus pandemic. Therefore, we want to focus our study on assessing the relationship between the coronavirus pandemic and psychosomatic symptoms that were not a direct 
consequence of COVID-19 and explore if there is any protective or risk factor that plays a role in this association.

\section{Materials and Methods}

\subsection{Participants}

For this study we used data from an anonymous online survey gathered in the Czech Republic during the coronavirus pandemic in April 2020 to depict the actual situation through the most critical time of the first wave of coronavirus pandemic. The final sample contained 1,431 Czech adult respondents (mean age=48.15, SD=16.43, 50.6\% male).

\subsection{Measures}

Health complaints were measured using questions focused on subjective health assessment inspired by the Health Behaviour in School-aged Children (HBSC) symptom checklist. These questions explore the prevalence of nine symptoms: (1) headache, (2) stomach ache, (3) backache, (4) intestinal problem, (5) feeling low, (6) irritability, (7) nervousness, (8) sleeping difficulties and (9) dizziness.

Religiosity was assessed by the question: "At present, would you call yourself a believer?".

Spirituality was assessed using the Daily Spiritual Experience Scale (DSES) [13], which measures the frequency of ordinary experiences of connection with transcendence in everyday life. In the present study, an adapted 15-item version of the scale validated in the Czech environment [14] was used.

Experiences during the pandemic were assessed by the question: "Has anything changed in your life in connection with the pandemic in the following areas?" These areas were: the feeling of (1) loneliness, (2) threat, (3) fear and anxiety, (4) helplessness, (5) hope.

\subsection{Statistical analyses}

First, we performed descriptive analyses of the study sample. Further, we evaluated the change in the frequency of the occurrence of individual psychosomatic symptoms before and during the coronavirus pandemic and the change in emotional state. Because of the non-normal distribution of data, we assessed the associations between the increased frequency of nine kinds of health complaints and sociodemographic characteristics using binary logistic regression models adjusted for age, gender and education. A Bonferroni correction was performed to correct for multiple testing. In the same way we assessed the associations of the increased frequency of nine kinds of health complaints with worsened feelings. We performed all analyses using the statistical software package IBM SPSS version 21 (IBM, New York, USA).

\section{Results and Discussion}

\subsection{The coronavirus pandemic and the incidence of health complaints}

Table 1 shows the change in the incidence of nine types of health complaints during the coronavirus pandemic compared to their incidence before it. In most respondents the pandemic did not affect the incidence of health complaints. In the remaining respondents either an increase or a decrease in the prevalence of health complaints was observed; however, for all nine types of health complaints, the increase was always higher than the decrease. These findings are consistent with other studies which suggested that the coronavirus pandemic is affecting both the physical $[4,7,15]$ and mental health $[4-7,16]$ of the population. The decrease in the frequency of health complaints could be caused by government measures, due to which some people had to stay at home and thus had more time for themselves. 
Table 1. The coronavirus pandemic and the incidence of health complaints.

\begin{tabular}{ccccccc}
\hline Health complaints & $\begin{array}{c}\text { Decrease in prevalence of health com- } \\
\text { plaints }\end{array}$ & No effect & \multicolumn{3}{c}{$\begin{array}{c}\text { Increase in prevalence of health com- } \\
\text { plaints }\end{array}$} \\
\hline & $\mathbf{N}$ & $\mathbf{\%}$ & $\mathrm{N}$ & $\%$ & $\mathrm{~N}$ & $\%$ \\
Headache & 64 & 4.5 & 1097 & 76.7 & 270 & 17.3 \\
Stomach ache & 43 & 3.0 & 126888.6 & 120 & 7.7 \\
Backache & 67 & 4.7 & 117982.4 & 183 & 11.7 \\
Intestinal problem & 52 & 3.6 & 127188.8 & 108 & 7.7 \\
Feeling low & 76 & 5.4 & 109876.7 & 257 & 16.5 \\
Irritability & 91 & 6.3 & 108175.5 & 259 & 16.6 \\
Nervousness & 100 & 7.1 & 106274.2 & 269 & 17.2 \\
Sleeping difficulties & 61 & 4.3 & 120884.4 & 162 & 10.3 \\
Dizziness & 24 & 1.7 & 135794.8 & 50 & 3.2 \\
Column total & 1431 & 100 & 1431 & 100 & 1431 & 100 \\
\hline
\end{tabular}

\subsection{The coronavirus pandemic and emotional state}

Table 2 shows the change in emotional state during the coronavirus pandemic compared to the normal time before it. Worsening of feelings was observed among $9.9 \%$ to $33.3 \%$ of respondents. These results are in line with other studies that argue that because of the coronavirus pandemic, people reported depressive symptoms, anxiety, stress [4-7], fear [7,17], anger [7], grief, and traumatic reactions [17]. Thus, it could be possible that during the coronavirus pandemic a wide range of emotions was affected, resulting in an overall deterioration of mental status.

Table 3. The coronavirus pandemic and emotional state.

\begin{tabular}{ccccc}
\hline Feelings & \multicolumn{2}{c}{ Increased negative feelings } & \multicolumn{2}{c}{ Others } \\
\hline Loneliness & $\mathbf{N}$ & $\mathbf{\%}$ & $\mathbf{N}$ & $\%$ \\
\hline Threat & 254 & 17.7 & 1177 & 82.3 \\
Fear and anxiety & 476 & 33.3 & 955 & 66.7 \\
Helpless & 373 & 26.1 & 1058 & 73.9 \\
Loss of hope & 349 & 24.4 & 1082 & 75.6 \\
Total & 142 & 9.9 & 1289 & 90.1 \\
& 1431 & 100 & 1431 & 100 \\
\hline
\end{tabular}

3.3. Associations of increased frequencies of health complaints with sociodemographic factors and with worsened feelings adjusted for age, gender and education

Further, we assessed the associations between the increased frequency of nine kinds of health complaints and sociodemographic characteristics or worsened feelings. Increasing age was significantly associated with a lower risk of increase of health complaints in six of the nine observed variables (exceptions were backache, intestinal problem and dizziness), with associations ranging from 1 to $2 \%$ decrease in the odds ratios (OR; $p<0.01$ and $\mathrm{p}<0.001$ ) for each year. These observations are in line with the findings of other authors who mention that during the coronavirus pandemic, older age was associated with less psychological distress [18], less anxiety [3,19], less depression and better overall mental health [19]. Consequently, better mental health may also be the reason for a lower risk of an increasing frequency of physical health complaints [20-22].

Our sociodemographic data also suggested that females showed a significantly higher risk of increased frequencies of health complaints compared to males in three of the nine observed variables (stomach ache, feeling low and nervousness), with ORs ranging from $1.52(\mathrm{p}<0.01)$ for nervousness to $2.24(\mathrm{p}<0.001)$ for feeling low. Above that, a tendency to a higher risk of increased frequencies of health complaints was observed for three other variables (headache, irritability and dizziness), which were significant before the Bonferroni correction. These findings are in line with other studies, which suggest that the 
coronavirus pandemic has a greater psychological effect on women [3,4,18,23-25]. Because of the relationship between the emotional and physical conditions of an individual [22], psychological problems may also lead to changes in physical health. This is also confirmed by a study of Beck et al. [15] conducted during the coronavirus pandemic, in which the authors reported that women had more sleeping difficulties than men.

Furthermore, we found that, in the most cases, education did not significantly affect the risk of increased frequencies of observed variable. An exception were respondents with secondary school with graduation, who had lower chances of increased frequencies of stomach ache $(\mathrm{OR}=0.41 ; \mathrm{p}<0.01)$. To the best of our knowledge, no one has thus far studied these associations. Thus, in order to be able to explain our results, more detailed analyses are needed. Furthermore, before Bonferroni correction, the results showed that respondents with a secondary education were more likely to report an increased frequency of headache, which is in contrast to other studies [26]. An explanation of these discrepancies could be that none of these studies was conducted during the coronavirus pandemic, in a non-standard and psychologically very demanding situation. However, this relationship needs to be verified in subsequent studies on a larger sample.

Socioeconomic status did not have a statistically significant effect on increased frequencies of health complaints after an application of the Bonferroni correction. However a tendency towards increased frequency of feeling low was observed among students. Further analyses on a larger sample are needed to confirm this relationship. A greater psychological impact on students was also observed in the study of Wang et al. [4,5] and in the study of Odrizola-Gonzalez et al. [5], where the authors observed a higher level of stress, anxiety and depression. Regarding the economic shutdown, which caused an increase in unemployment, some students could have been worried about unemployment when they graduate from college in the near future [17] or worried about their educational process (e.g. extending the length of study, impossibility of practice etc.).

Furthermore, neither marital status nor faith were significantly associated with increased frequencies of health complaints, and we observed only one significant association with spirituality. Highly spiritual people were more likely to report increased frequency of dizziness, with a $2 \%$ increase in the odds ratio (OR 1.03; $\mathrm{p}<0.01$ ) for each point of the DSES scale. Other associations were not significant, which is in contrast with our earlier study, where we suggested that spirituality could decrease the prevalence of health complaints in Czech adolescents [27]. These discrepancies may be caused by the respondents' age (adolescents vs. adults) or by the differencies in measurement tools (SWBS vs. DSES). However, due to the small number of respondents with increased frequencies of dizziness, it is very difficult to interpret the data well, and before making any conclusions, it is necessary to verify these results on a larger sample.

We further found that respondents' psychological deterioration is associated with an increased risk of health complaints, with associations ranging from $O R=1.61(p<0.01)$ to $\mathrm{OR}=3.69(\mathrm{p}<0.001)$. The greatest effect was observed in case of worsening feelings of fear and anxiety. These were associated with higher chances of increased frequencies of health complaints in six of the nine observed variables (exception were backache, intestinal problems and dizziness), with associations ranging from $\mathrm{OR}=1.61(\mathrm{p}<0.01)$ for intestinal problems to $\mathrm{OR}=3.56(\mathrm{p}<0.001)$ for feeling low. As expected, fear and anxiety had a greatest effect. However, we also observed associations with physical health. Thus, our findings further support the idea of the association between mental and physical health $[20-22,28]$, as we mentioned above.

\section{Conclusion}

Our findings suggest that in the Czech Republic, the initial phase of the coronavirus pandemic and associated government measures to prevent the spread of the virus influenced the occurrence of psychosomatic health complaints. Respondents also reported worsened feelings compared to the pre-pandemic period. Among the risk factors associated with a higher risk of increased frequency of health complaints are younger age, female gender, negative emotions and potentially, also a student status and highest 
achieved secondary school education and high spirituality. Our research results are of a great practical significance and can be immediately applied to optimize the response to similar future situations as well as the long-term effect of the current pandemic. Further research in this area is needed with respect to the clinical applicability of these findings.

Author Contributions: Conceptualization, R.Z. and K.M..; methodology, R.Z., K.M., J.P.v.D. and P.T..; formal analysis, R.Z. and K.M..; investigation, R.Z., K.M. and P.T.; resources, P.T.; data curation, P.T..; writing - original draft preparation, R.Z. and K.M.; writing - review and editing, J.P.v.D. and P.T..; visualization, R.Z.; supervision, J.P.v.D. and P.T..; project administration, J.P.v.D. and P.T.; funding acquisition, P.T. All authors have read and agreed to the published version of the manuscript.

Funding: This research was supported by the Sts Cyril and Methodius Faculty of Theology of the Palacký University Olomouc internal project Spiritual, Psychological, Social and Biological Determinants of Health (grant number IGA-CMTF-2020-006).

Conflicts of Interest: The authors declare no conflict of interest.

\section{References}

1. Wang, C.; Horby, P.W.; Hayden, F.G.; Gao, G.F. A novel coronavirus outbreak of global health concern. Lancet 2020, 395, 470473, doi:10.1016/s0140-6736(20)30185-9.

2. WHO. Naming the coronavirus disease (COVID-19) and the virus that causes it. Availabe online: https://www.who.int/emergencies/diseases/novel-coronavirus-2019/technical-guidance/naming-the-coronavirus-disease-(covid-2019)-and-the-virus-thatcauses-it (accessed on

3. Wang, Y.; Di, Y.; Ye, J.; Wei, W. Study on the public psychological states and its related factors during the outbreak of coronavirus disease 2019 (COVID-19) in some regions of China. Psychology, Health $\mathcal{E}$ Medicine 2020, 1-10, doi:10.1080/13548506.2020.1746817.

4. Wang, C.; Pan, R.; Wan, X.; Tan, Y.; Xu, L.; Ho, C.S.; Ho, R.C. Immediate Psychological Responses and Associated Factors during the Initial Stage of the 2019 Coronavirus Disease (COVID-19) Epidemic among the General Population in China. Int J Environ Res Public Health 2020, 17, doi:10.3390/ijerph17051729.

5. Odriozola-Gonzalez, P.; Planchuelo-Gomez, A.; Irurtia, M.J.; de Luis-Garcia, R. Psychological effects of the COVID-19 outbreak and lockdown among students and workers of a Spanish university. Psychiatry research 2020, 290, 113108-113108, doi:10.1016/j.psychres.2020.113108.

6. Wang, C.Y.; Pan, R.Y.; Wan, X.Y.; Tan, Y.L.; Xu, L.K.; McIntyre, R.S.; Choo, F.N.; Tran, B.; Ho, R.; Sharma, V.K., et al. A longitudinal study on the mental health of general population during the COVID-19 epidemic in China. Brain Behavior and Immunity 2020, 87, 40-48, doi:10.1016/j.bbi.2020.04.028.

7. Torales, J.; O'Higgins, M.; Castaldelli-Maia, J.M.; Ventriglio, A. The outbreak of COVID-19 coronavirus and its impact on global mental health. International Journal of Social Psychiatry 2020, 66, 317-320, doi:10.1177/0020764020915212.

8. Santarelli, L.; Rapisarda, V.; Fago, L.; Vella, F.; Ramaci, T.; Ledda, C.; Bracci, M. Relation between psychosomatic disturbances and job stress in video display unit operators. Work-a Journal of Prevention Assessment E Rehabilitation 2019, 64, 303-310, doi:10.3233/wor-192993.

9. Williams, K.; Lund, T.J.; Liang, B.; Mousseau, A.D.; Spencer, R. Associations between Stress, Psychosomatic Complaints, and Parental Criticism among Affluent Adolescent Girls. Journal of Child and Family Studies 2018, 27, 1384-1393, doi:10.1007/s10826017-0991-2.

10. Yu, N.X.; Chan, J.S.M.; Ji, X.W.; Wan, A.H.Y.; Ng, S.M.; Yuen, L.P.; Chan, C.L.W.; Chan, C.H.Y. Stress and psychosomatic symptoms in Chinese adults with sleep complaints: mediation effect of self-compassion. Psychology Health $\mathcal{E}$ Medicine 2019, 24, 241252, doi:10.1080/13548506.2018.1546014.

11. Xiao, H.; Zhang, Y.; Kong, D.S.; Li, S.Y.; Yang, N.X. The Effects of Social Support on Sleep Quality of Medical Staff Treating Patients with Coronavirus Disease 2019 (COVID-19) in January and February 2020 in China. Medical Science Monitor 2020, 26, doi:10.12659/msm.923549.

12. Wu, K.L.; Wei, X.M. Analysis of Psychological and Sleep Status and Exercise Rehabilitation of Front-Line Clinical Staff in the Fight Against COVID-19 in China. Medical Science Monitor Basic Research 2020, 26, 7, doi:10.12659/msmbr.924085.

13. Underwood, L. Ordinary Spiritual Experience: Qualitative Research, Interpretive Guidelines, and Population Distribution for the Daily Spiritual Experience Scale. Archive for the Psychology of Religion 2006, 28, 181-218.

14. Malinakova, K.; Trnka, R.; Sarnikova, G.; Smekal, V.; Furstova, J.; Tavel, P. Psychometric evaluation of the Daily Spiritual Experience Scale (DSES) in the Czech environment. Ceskoslovenska Psychologie 2018, 62, 100-113.

15. Beck, F.; Leger, D.; Fressard, L.; Peretti-Watel, P.; Verger, P.; Coconel, G. Covid-19 health crisis and lockdown associated with high level of sleep complaints and hypnotic uptake at the population level. Journal of Sleep Research, doi:10.1111/jsr.13119.

16. Sun, S.; Lin, D.; Operario, D. Need for a population health approach to understand and address psychosocial consequences of COVID-19. Psychological trauma : theory, research, practice and policy 2020, doi:10.1037/tra0000618. 
17. Sun, S.F.; Lin, D.H.; Operario, D. Need for a Population Health Approach to Understand and Address Psychosocial Consequences of COVID-19. Psychological Trauma-Theory Research Practice and Policy 2020, 12, S25-S27, doi:10.1037/tra0000618.

18. Gomez-Salgado, J.; Andres-Villas, M.; Dominguez-Salas, S.; Diaz-Milanes, D.; Ruiz-Frutos, C. Related Health Factors of Psychological Distress During the COVID-19 Pandemic in Spain. International journal of environmental research and public health 2020, 17, doi:10.3390/ijerph17113947.

19. Bruine de Bruin, W. Age differences in COVID-19 risk perceptions and mental health:Evidence from a national US survey conducted in March 2020. The journals of gerontology. Series B, Psychological sciences and social sciences 2020, doi:10.1093/geronb/gbaa074.

20. Ohrnberger, J.; Fichera, E.; Sutton, M. The relationship between physical and mental health: A mediation analysis. Social Science \& Medicine 2017, 195, 42-49, doi:https://doi.org/10.1016/j.socscimed.2017.11.008.

21. Chang, H.-Y.; Chiou, C.-J.; Chen, N.-S. Impact of mental health and caregiver burden on family caregivers' physical health. Archives of Gerontology and Geriatrics 2010, 50, 267-271, doi:https://doi.org/10.1016/j.archger.2009.04.006.

22. Lee, Y.S.; Jung, W.M.; Jang, H.; Kim, S.; Chung, S.Y.; Chae, Y. The dynamic relationship between emotional and physical states: an observational study of personal health records. Neuropsychiatric Disease and Treatment 2017, 13, 411-419, doi:10.2147/ndt.s120995.

23. Zhou, S.-J.; Zhang, L.-G.; Wang, L.-L.; Guo, Z.-C.; Wang, J.-Q.; Chen, J.-C.; Liu, M.; Chen, X.; Chen, J.-X. Prevalence and sociodemographic correlates of psychological health problems in Chinese adolescents during the outbreak of COVID-19. European Child \& Adolescent Psychiatry 2020, doi:10.1007/s00787-020-01541-4.

24. Ozdin, S.; Bayrak Ozdin, S. Levels and predictors of anxiety, depression and health anxiety during COVID-19 pandemic in Turkish society: The importance of gender. International Journal of Social Psychiatry 2020, doi:10.1177/0020764020927051.

25. Liu, N.; Zhang, F.; Wei, C.; Jia, Y.; Shang, Z.; Sun, L.; Wu, L.; Sun, Z.; Zhou, Y.; Wang, Y., et al. Prevalence and predictors of PTSS during COVID-19 Outbreak in China Hardest-hit Areas: Gender differences matter. Psychiatry Research 2020, 112921, doi:https://doi.org/10.1016/j.psychres.2020.112921.

26. Queiroz, L.P.; Peres, M.F.P.; Kowacs, F.; Piovesan, E.J.; Ciciarelli, M.C.; Souza, J.A.; Zukerman, E. Chronic daily headache in Brazil: a nationwide population-based study. Cephalalgia 2008, 28, 1264-1269, doi:10.1111/j.1468-2982.2008.01670.x.

27. Zidkova, R.; Glogar, P.; Polackova Solcova, I.; P van Dijk, J.; Kalman, M.; Tavel, P.; Malinakova, K. Spirituality, Religious Attendance and Health Complaints in Czech Adolescents. International journal of environmental research and public health 2020, 17, doi:10.3390/ijerph17072339.

28. Salovey, P.; Rothman, A.J.; Detweiler, J.B.; Steward, W.T. Emotional states and physical health. American Psychologist 2000, 55, 110-121, doi:10.1037/0003-066x.55.1.110. 